\title{
HUMAN CORONAVIRUS NL63 INFECTION IS ASSOCIATED WITH CROUP
}

\author{
Lia van der Hoek, Klaus Sure, Gabriele Ihorst, Alexander Stang, \\ Krzysztof Pyrc, Maarten F. Jebbink, Gudula Petersen, Johannes Forster, \\ Ben Berkhout, and Klaus Überla*
}

\section{INTRODUCTION}

Respiratory tract infections are among the most frequent diseases in the first years of life. Although there is a large number of viruses that are known to be involved in symptomatic respiratory tract infections, including respiratory syncytial virus (RSV), influenza virus (INF), parainfluenza virus (PIV), and human metapneumovirus, none of the known pathogens is detected in a substantial number of cases. Recently we identified a novel coronavirus in a child with bronchiolitis: human coronavirus NL63 (HCoVNL63). ${ }^{1,2}$ This virus, together with SARS-CoV, is one of the new members of the Coronaviridae family. ${ }^{3-6}$

Screening of respiratory samples in Amsterdam and Rotterdam confirmed that HCoV-NL63 is circulating among humans with respiratory disease in The Netherlands. ${ }^{1,7}$ To investigate the prevalence of HCoV-NL63 and its involvement in respiratory diseases, we now analyzed 949 samples from the Paediatric Respiratory Infection in Germany (PRI.DE) study, a prospective population-based study on lower respiratory tract infections (LRTIs) in children under 3 year of age in Germany. ${ }^{8,9}$ The PRI.DE study represents the German population by (i) including multicenter sampling (one city each in the north, east, south, and west of the country) and by (ii) recruiting children in pediatric practices and in referral children's hospitals. We were particularly interested in the presence of HCoV-NL63 in respiratory disease for which no other viral pathogen could be detected, in order to identify clinical symptoms associated with HCoV-NL63 infection. Nasopharyngeal secretion (NPS) of the patients had already been tested for

\footnotetext{
* Lia van der Hoek, Krzysztof Pyrc, Maarten F. Jebbink, Ben Berkhout, University of Amsterdam, Amsterdam, The Netherlands. Klaus Sure, Alexander Stang, Klaus Überla, Ruhr-University Bochum, Bochum, Germany. Gabriele Ihorst, University Hospital, Freiburg, Germany. Gudula Petersen, Wyeth Pharma, Münster, Germany. Johannes Forster, St. Josefs Hospital, Freiburg, Germany. 
RSV, INF, and PIV, the principal viruses responsible for LRTI in young children. ${ }^{8}$ However, RNA of these viruses could not be detected in $58 \%$ of samples for outpatients and $51 \%$ of samples for hospitalized patients. A second study that examined a subset of these negative samples for human metapneumovirus RNA showed that this virus could be detected in only $0.3 \%$ of the patients. To explore the potential contribution of HCoVNL63 to LRTI and to define clinical symptoms associated with HCoV-NL63 infection, a subset of the PRI.DE samples were analyzed in this study by a HCoV-NL63-specific quantitative real-time RT-PCR.

\section{RESULTS}

\subsection{HCoV-NL63 Infections}

Of the 949 PRI.DE samples tested, 392 were from outpatients at the four study sites, and the remaining 557 samples were from hospitalized patients. In total, 49 of the 949 samples (5.2\%) were positive for HCoV-NL63 (for methods see PloS Medicine 2(8):e240 764-770). More HCoV-NL63 infections were found in the outpatients (31 patients, 7.9\%) than in hospitalized patients (18 patients, $3.2 \%, p=0.003$ ). Various clinical diagnoses of lower respiratory tract disease were given for the HCoV-NL63-positive patients, including croup, bronchitis, bronchiolitis, and pneumonia (Tables 1 and 2). The ages of the HCoV-NL63-infected children ranged from 0 to 2.9 years, with a median age of 0.7 year for the hospitalized patients and 1.5 year for the outpatients. As may be expected based on knowledge of other human coronaviruses, there is a strong seasonal distribution of HCoV-NL63, with preferential detection in the period between November and March (Figure 1). Peaks were observed in December 2000 (14\% of patients positive) and February 2001 (12\% of patients positive). We found no positive samples in the winter months of 1999 and 2000, but the analyzed PRI.DE samples were unequally distributed and only 17 samples were analysed from the period December 1999 to March 2000.

\subsection{HCoV-NL63 Co-infections with RSV-A and PIV3}

Because the same samples had been tested previously for the presence of RSV, PIV, and INF RNA, ${ }^{8}$ the HCoV-NL63-positive samples were analyzed for co-infections with these viruses. Co-infections were apparent in 29 of the 49 HCoV-NL63-positive samples: 20 patients were co-infected with RSV-A, four with RSV-B, and five with PIV3. Double infections were observed in the hospitalized patients with HCoV-NL63 (72\%) but also in the outpatients $(52 \%)$. HCoV-NL63 co-infection with RSV-A occurred predominantly in the hospitalized patients (61\%) rather than the outpatient group (29\%). In contrast, HCoV-NL63 co-infections with PIV3 were exclusively present in the outpatient group $(16 \%)$. Similar trends were also observed when looking at the overall prevalence of the viruses: RSV-A occurred in $32 \%$ of hospitalized patients versus $21 \%$ of outpatients, and PIV3 occurred in $5 \%$ of hospitalized patients and $8 \%$ of outpatients. ${ }^{8}$ The RNA load of HCoV-NL63 differed considerably from less than 225 copies/ml (but detectable) to $9 \mathrm{x}$ $10^{7}$ copies/ml aspirate. Interestingly, the HCoV-NL63 load was significantly higher in samples with undetectable levels of the other viral RNAs (median viral load $2.1 \times 10^{6}$ copies $/ \mathrm{ml})$ than in samples that had co-infections with RSV or PIV3 $\left(2.7 \times 10^{2}\right.$ copies $/ \mathrm{ml}$, $p=0.0006$; Figure 2). 


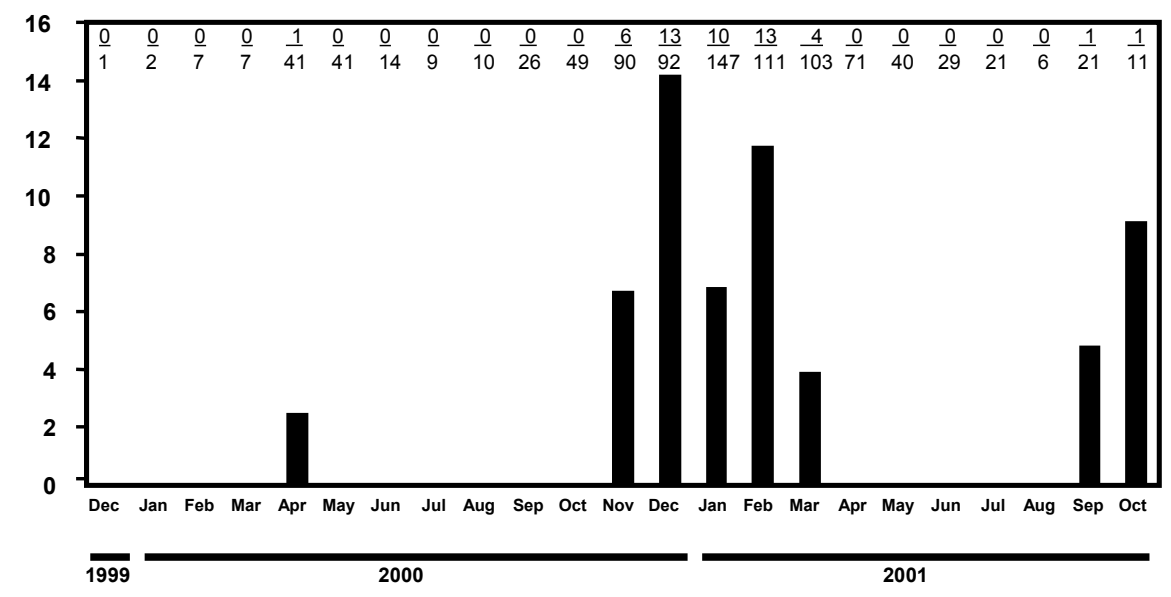

Figure 1. Seasonal distribution of HCoV-NL63. Bars represent the percentage of HCoV-NL63 positive samples per month. Digits above the columns for each month give the number of HCoV-NL63 positive samples over the number of samples tested. Y-axis: HCoV-NL63-positive patients (\%).

Table 1. HCoV-NL63-positive hospital patients.

\begin{tabular}{|c|c|c|c|c|c|c|c|}
\hline $\begin{array}{l}\text { Patient } \\
\text { number }\end{array}$ & $\begin{array}{c}\text { Age } \\
\text { (years) }\end{array}$ & Sex & $\begin{array}{l}\text { Sampling } \\
\text { month }\end{array}$ & Diagnosis & Fever & $\begin{array}{l}\text { Other } \\
\text { virus }\end{array}$ & $\begin{array}{c}\text { HCoV-NL63 } \\
\text { RNA load } \\
\text { (copies/ml) }\end{array}$ \\
\hline $10-343^{a}$ & 1.88 & $\mathrm{~F}$ & $12 / 00$ & Pneumonia & $\mathrm{N}$ & RSV-B & 26200 \\
\hline $10-397$ & 0.09 & $\mathrm{~F}$ & $1 / 01$ & Bronchiolitis & $\mathrm{N}$ & RSV-A & 4520 \\
\hline $10-416$ & 0.11 & M & $2 / 01$ & Bronchitis & $\mathrm{N}$ & RSV-A & 18800 \\
\hline $10-447$ & 0.86 & M & $2 / 01$ & Croup/ Bronchiolitis & $\mathrm{N}$ & - & $\operatorname{pos}(\leq 225)$ \\
\hline $11-275$ & 2.23 & M & $12 / 00$ & Croup/ Bronchiolitis & $\mathrm{Y}$ & - & 7380000 \\
\hline $11-395$ & 0.78 & $\mathrm{~F}$ & $3 / 01$ & Bronchiolitis & $\mathrm{Y}$ & RSV-A & $\operatorname{pos}(\leq 225)$ \\
\hline $20-443$ & 0.65 & M & $1 / 01$ & Bronchiolitis & $\mathrm{N}$ & RSV-A & $\operatorname{pos}(\leq 225)$ \\
\hline $20-454$ & 0.17 & $\mathrm{~F}$ & $2 / 01$ & Bronchiolitis & $\mathrm{N}$ & RSV-A & $\operatorname{pos}(\leq 225)$ \\
\hline $30-317$ & 0.08 & $\mathrm{~F}$ & $2 / 01$ & Bronchiolitis & $\mathrm{Y}$ & RSV-B & 667 \\
\hline $40-489$ & 0.22 & $\mathrm{~F}$ & $12 / 00$ & Bronchitis & $\mathrm{N}$ & RSV-A & $\operatorname{pos}(\leq 225)$ \\
\hline $40-546^{b}$ & 0.01 & $\mathrm{M}$ & $12 / 00$ & Bronchiolitis & $\mathrm{N}$ & RSV-A & 1360000 \\
\hline $40-713$ & 0.99 & $\mathrm{~F}$ & $2 / 01$ & Croup/Bronchitis & $\mathrm{Y}$ & - & 53600000 \\
\hline $40-715$ & 0.76 & M & $2 / 01$ & Bronchiolitis & $\mathrm{N}$ & - & $\operatorname{pos}(\leq 225)$ \\
\hline $40-717$ & 0.13 & $\mathrm{~F}$ & $2 / 01$ & Pneumonia & $\mathrm{Y}$ & RSV-A & $\operatorname{pos}(\leq 225)$ \\
\hline $40-723$ & 0.10 & $\mathrm{M}$ & $2 / 01$ & Bronchiolitis & $\mathrm{N}$ & RSV-A & $\operatorname{pos}(\leq 225)$ \\
\hline $40-735$ & 1.05 & $\mathrm{~F}$ & $2 / 01$ & Pneumonia & $\mathrm{Y}$ & RSV-A & $\operatorname{pos}(\leq 225)$ \\
\hline $40-746$ & 1.80 & $\mathrm{~F}$ & $2 / 01$ & Pneumonia & $\mathrm{N}$ & - & 17400000 \\
\hline $40-764$ & 1.52 & $\mathrm{~F}$ & $2 / 01$ & Pneumonia & $\mathrm{Y}$ & RSV-A & $\operatorname{pos}(\leq 225)$ \\
\hline
\end{tabular}

${ }^{a}$ The patient number is preceded by the code of the medical center: 10: Freiburg SJK; 11: Freiburg UKL; 20: Dresden; 30: Bochum; 40: Hamburg; 12 and 13: Freiburg; 22, 23 and 24: Dresden; 34: Bochum.; 43: Hamburg.

${ }^{\mathrm{b}}$ Nosocomial infection. 


\subsection{Association of HCoV-NL63 Infection with Clinical Symptoms}

The high frequency of co-infections in HCoV-NL63-positive samples makes it difficult to define HCoV-NL63-induced symptoms. However, in 20 of the $49 \mathrm{HCoV}$ NL63-positive samples no other virus (RSV, PIV, or INF) could be detected. At least 14 of these samples also had a high viral RNA load ( $>10,000$ copies $/ \mathrm{ml}$ aspirate), cases that may be best suited to study the clinical symptoms associated with HCoV-NL63 infection. Six of the 14 children (43\%) of this group had croup compared with only 54 of 900 HCoV-NL63-negative children $(6 \%, p<0.0001)$. A similar high frequency of croup (45\%) was also observed for the 20 samples in which only HCoV-NL63 RNA was detected, independent of the viral load. The association of HCoV-NL63 with croup also held for all analysed samples: $24 \%$ in the HCoV-NL63-positive group had croup compared with $6 \%$ of the $900 \mathrm{HCoV}-\mathrm{NL} 63$-negative patients $(p<0.0001)$. HCoV-NL63 was detectable in $17.4 \%$ of all samples from croup patients.

Table 2. HCoV-NL63-positive outpatients.

\begin{tabular}{|c|c|c|c|c|c|c|c|}
\hline $\begin{array}{l}\text { Patient } \\
\text { number }\end{array}$ & $\begin{array}{c}\text { Age } \\
\text { (years) }\end{array}$ & Sex & $\begin{array}{c}\text { Sampling } \\
\text { month }\end{array}$ & Diagnosis & Fever & $\begin{array}{l}\text { Other } \\
\text { virus }\end{array}$ & $\begin{array}{c}\text { HCoV-NL63 } \\
\text { RNA load } \\
\text { (copies/ml) }\end{array}$ \\
\hline $12-75$ & 0.95 & $\mathrm{M}$ & $12 / 00$ & Croup & $\mathrm{N}$ & - & 155000 \\
\hline $12-86$ & 0.71 & $\mathrm{~F}$ & $1 / 01$ & Bronchitis & $\mathrm{N}$ & - & 2240 \\
\hline $12-107$ & 1.02 & M & $3 / 01$ & Bronchiolitis & $\mathrm{N}$ & RSV-A & 333 \\
\hline $12-108$ & 1.02 & M & $3 / 01$ & Bronchitis & $\mathrm{N}$ & RSV-A & $\operatorname{pos}(\leq 225)$ \\
\hline $12-137$ & 1.25 & M & $9 / 01$ & Bronchiolitis & $\mathrm{N}$ & RSV-A & $\operatorname{pos}(\leq 225)$ \\
\hline $13-255$ & 2.75 & $\mathrm{~F}$ & $11 / 00$ & Bronchiolitis & $\mathrm{N}$ & PIV3 & 26200 \\
\hline $13-316$ & 1.01 & $\mathrm{M}$ & $1 / 01$ & Croup & $\mathrm{Y}$ & PIV3 & 6430000 \\
\hline $13-342$ & 1.07 & M & $1 / 01$ & Croup & $\mathrm{N}$ & - & 27400000 \\
\hline $22-102$ & 0.37 & M & $4 / 00$ & Bronchitis & $\mathrm{N}$ & - & 5240000 \\
\hline $22-136$ & 1.08 & $\mathrm{~F}$ & $11 / 00$ & Croup & $\mathrm{Y}$ & PIV3 & 571 \\
\hline $22-140$ & 2.15 & $\mathrm{~F}$ & $11 / 00$ & Croup & $\mathrm{N}$ & PIV3 & $\operatorname{pos}(\leq 225)$ \\
\hline $22-143$ & 1.51 & M & $11 / 00$ & Croup & $\mathrm{Y}$ & - & $\operatorname{pos}(\leq 225)$ \\
\hline $22-158$ & 1.41 & $\mathrm{~F}$ & $11 / 01$ & Bronchiolitis & $\mathrm{N}$ & RSV-A & 333 \\
\hline $22-170$ & 2.33 & $\mathrm{M}$ & $1 / 01$ & Bronchitis & $\mathrm{Y}$ & RSV-B & 548 \\
\hline $22-195$ & 2.09 & M & $2 / 01$ & Bronchiolitis & $\mathrm{N}$ & RSV-A & 197000 \\
\hline $22-198$ & 1.85 & $\mathrm{M}$ & $2 / 01$ & Bronchiolitis & $\mathrm{Y}$ & RSV-A & $\operatorname{pos}(\leq 225)$ \\
\hline $22-215$ & 0.78 & $\mathrm{M}$ & $3 / 01$ & Croup & $\mathrm{Y}$ & - & 25000000 \\
\hline $23-66$ & 2.03 & M & $12 / 00$ & Bronchitis & $\mathrm{N}$ & - & 2860000 \\
\hline $23-68$ & 2.45 & $\mathrm{~F}$ & $12 / 00$ & Bronchiolitis & $\mathrm{Y}$ & RSV-A & 140000 \\
\hline $23-69$ & 1.75 & M & $12 / 00$ & Croup & $\mathrm{N}$ & - & $\operatorname{pos}(\leq 225)$ \\
\hline $23-95$ & 1.86 & $\mathrm{M}$ & $1 / 01$ & Bronchitis & $\mathrm{N}$ & - & 250000 \\
\hline $24-105$ & 1.11 & $\mathrm{M}$ & $2 / 01$ & Bronchitis & $\mathrm{Y}$ & RSV-B & 136 \\
\hline $24-178$ & 2.21 & M & $11 / 00$ & Bronchiolitis & $\mathrm{Y}$ & PIV3 & $\operatorname{pos}(\leq 225)$ \\
\hline 24-194 & 1.88 & $\mathrm{M}$ & $12 / 00$ & Bronchitis & $\mathrm{Y}$ & - & 1950000 \\
\hline $24-202$ & 2.91 & $\mathrm{M}$ & $12 / 00$ & Bronchiolitis & Y & RSV-A & 12400 \\
\hline $24-230$ & 2.38 & M & $1 / 01$ & Bronchiolitis & $\mathrm{Y}$ & - & 2290000 \\
\hline $24-232$ & 2.63 & M & $1 / 01$ & Bronchiolitis & $\mathrm{Y}$ & - & 11400000 \\
\hline $34-162$ & 0.48 & $\mathrm{~F}$ & $10 / 01$ & Bronchitis & $\mathrm{N}$ & - & 91200000 \\
\hline $43-10$ & 2.12 & $\mathrm{M}$ & $11 / 00$ & Bronchiolitis & $\mathrm{Y}$ & - & $\operatorname{pos}(\leq 225)$ \\
\hline $43-15$ & 0.45 & M & $12 / 00$ & Bronchiolitis & $\mathrm{N}$ & RSV-A & pos $(\leq 225)$ \\
\hline $43-18$ & 0.51 & $\mathrm{~F}$ & $12 / 00$ & Croup & $\mathrm{N}$ & - & 28600 \\
\hline
\end{tabular}


The chance of croup is estimated to be 6.6 times higher in HCoV-NL63-positive LRTI patients than in HCoV-NL63-negative LRTI patients (95\% confidence interval 3.1-14.2). In addition to croup, we also observed bronchitis $(n=6$, of which one also had had croup), bronchiolitis ( $n=3$, of which one also had croup), and pneumonia $(n=1)$ in the 14 patients with a high HCoV-NL63 load. None of these diseases was significantly associated with single infection with HCoV-NL63.

\section{DISCUSSION}

The newly discovered coronavirus HCoV-NL63 was detected in a considerable number of nasal aspirates of children under the age of 3 year with LRTIs. With an overall occurrence of $5.2 \%$, it is the third most frequently detected pathogen in this patient group, in which RSV is detected in $31.4 \%$, PIV3: $9.6 \%$, PIV1: $2.5 \%$, INF A or INF B:2.4\%, and PIV2: $0.6 \%$. These viruses were detected with similar frequency in the PRI.DE study ${ }^{8}$, arguing against a bias during selection of the analyzed samples. HCoV-NL63 is more frequently found in the outpatient group with LRTI $(7.9 \%)$ than among hospitalized patients $(3.2 \%)$. PIV3 follows the same pattern $(8 \%$ and $5 \%$, respectively), but the reverse pattern is observed for RSV (21\% and 32\%, respectively). ${ }^{8}$ Thus, HCoV-NL63 infection seems to be less pathogenic than RSV infection. Hospitalized HCoV-NL63positive patients are frequently co-infected with RSV. Nevertheless, several severe disease cases that required uptake in the intensive care unit were linked exclusively to HCoV-NL63 infection in this and our previous survey. ${ }^{1}$

Croup is a common manifestation of LRTI in children. The cause is generally assumed to be a respiratory virus and PIV1 has frequently been implicated. ${ }^{10}$ Among the 69 samples of patients analyzed with croup, croup was indeed frequently linked to PIV1 (14.5\%), but PIV3 (15.9\%), RSV-A (13.0\%), PIV2 (7.2\%), and RSV-B (1.4\%) were also

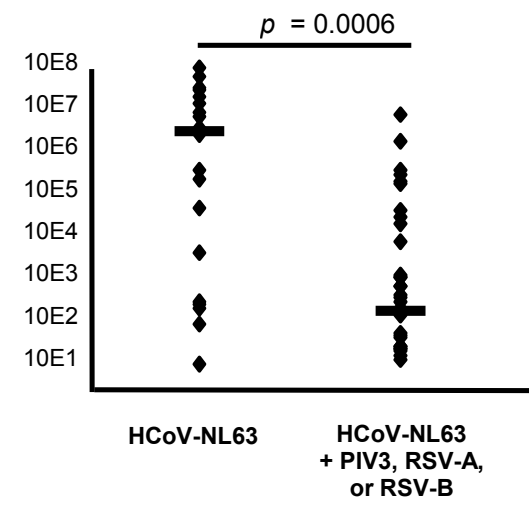

Figure 2. HCoV-NL63 viral load in single and double infections. The median viral load in the two groups is indicated together with the $p$-value, showing a significant difference between the singly HCoV-NL63 infected group and the group with a co-infection of either RSV or PIV3. Y-axis: HCoV-NL63 viral load (RNA copies $/ \mathrm{ml})$. 
detected in a considerable percentage of samples. HCoV-NL63 could be detected in $17.4 \%$ of these croup patients and was therefore the most frequently identified respiratory virus for croup. Since most of the samples tested were derived from the year 2000-2001, we cannot exclude that the high percentage of HCoV-NL63-positive samples is due to a strong viral activity in this particular year, and long-term studies are needed to determine whether HCoV-NL63 infections occur in cycles peaking every two to three years as observed for other respiratory viruses.

Croup has been reported to occur mostly in boys, and it shows a peak occurrence in the second year of life and predominantly in the late fall or early winter season. ${ }^{10} \mathrm{HCoV}$ NL63 infection seems to follow these trends: the ratio of boys infected to girls infected is $10: 4$, the median age in the outpatient group with HCoV-NL63 is 1.55 years, and this virus is circulating mainly in the winter months. Thus, it will be of interest to study the underlying biological reasons for the increased susceptibility of young boys to HCoVNL63, as this may also explain the higher number of male patients with croup. A preferential occurrence in boys has been described for other respiratory diseases including asthma, ${ }^{11}$ and human coronavirus infections have previously been associated with exacerbations of asthma. ${ }^{12}$ It will therefore also be of interest to study this link for HCoV-NL63.

Quantitative PCR analysis for HCoV-NL63 revealed a significantly lower HCoVNL63 viral load in patients co-infected with RSV or PIV3 than in patients infected with HCoV-NL63 alone. This interference effect might be explained by direct competition for the same target cell in the respiratory organs or an elevated activation status of innate immune responses. Prolonged persistence of HCoV-NL63 at low levels is another explanation. The HCoV-NL63 load was found to vary with respect to the time of sampling relative to the time of disease onset, with the higher viral loads in early samples (day 1 or 2 after disease onset). This most likely reflects viral clearance by the immune system. This timing effect may also relate to the differences in HCoV-NL63 load in single versus double infections. For instance, an initial HCoV-NL63 infection may set the stage for a subsequent RSV infection. At the time that this second virus is causing symptoms and NPS samples are collected, the HCoV-NL63 infection may already be under control by the immune system.

In conclusion, our study revealed that $\mathrm{HCoV}-\mathrm{NL} 63$ belongs to the group of most frequently detected viruses in children under 3 year of age with LRTI and that this virus is strongly associated with croup. Recent articles on HCoV-NL63 show that this virus is spread worldwide (Australia, Canada, Japan, Belgium, United States, and France). Thus, HCoV-NL63 is a human respiratory virus that should be added to the list of pathogens that can cause numerous LRTIs in young children.

Financial support was received from Wyeth Pharma, Münster, Germany. The Center for Clinical Trials receives funding from the German Federal Ministry of Education and Research (BMBF).

\section{REFERENCES}

1. L. van der Hoek, K. Pyrc, M. F. Jebbink, W. Vermeulen-Oost, R. J. Berkhout, et al., Identification of a new human coronavirus, Nat. Med. 10, 368-373 (2004).

2. K. Pyrc, M. F. Jebbink, B. Berkhout, and L. van der Hoek, Genome structure and transcriptional regulation of human coronavirus NL63, J. Virol. 1, 7 (2004). 
3. J. S. Peiris, S. T. Lai, L. L. Poon, Y. Guan, L. Y. Yam, et al., Coronavirus as a possible cause of severe acute respiratory syndrome, Lancet 361, 1319-1325 (2003).

4. C. Drosten, S. Gunther, W. Preiser, S. van der Werf, H. R. Brodt, et al., Identification of a novel coronavirus in patients with severe acute respiratory syndrome, N. Engl. J. Med. 348, 1967-1976 (2003).

5. Osterhaus AD, Fouchier RA, Kuiken T (2004) The aetiology of SARS: Koch's postulates fulfilled. Philos Trans R Soc Lond B Biol Sci 359: 1081-1082.

6. P. C. Woo, S. K. Lau, C. M. Chu, K. H. Chan, H. W. Tsoi, et al., Characterization and complete genome sequence of a novel coronavirus, coronavirus HKU1, from patients with pneumonia, J. Virol. 79, 884-895 (2005).

7. R. A. Fouchier, N. G. Hartwig, T. M. Bestebroer, B. Niemeyer, J. C. de Jong, et al., A previously undescribed coronavirus associated with respiratory disease in humans, Proc. Natl. Acad. Sci. USA 101, 6212-6216 (2004)

8. J. Forster, G. Ihorst, C. H. Rieger, V. Stephan, H. D. Frank, et al., Prospective population-based study of viral lower respiratory tract infections in children under 3 years of age (the PRIDE study), Eur. J. Pediatr. 163, 709-716 (2004)

9. B. Konig, W. Konig, R. Arnold, H. Werchau, G. Ihorst, et al., Prospective study of human metapneumovirus infection in children less than 3 years of age, J. Clin. Microbiol. 42, 4632-4635 (2004).

10. F. W. Denny, T. F. Murphy, W. A. Clyde, Jr., A. M. Collier, and F. W. Henderson, Croup: An 11-year study in a pediatric practice, Pediatrics 71, 871-876 (1983).

11. E. F. Ellis, Asthma in childhood, J. Allergy Clin. Immunol. 72, 526-539 (1983)

12. K. McIntosh, E. F. Ellis, L. S. Hoffman, T. G. Lybass, J. J. Eller, et al., The association of viral and bacterial respiratory infections with exacerbations of wheezing in young asthmatic children, J. Pediatr. 82, 578-590 (1973). 